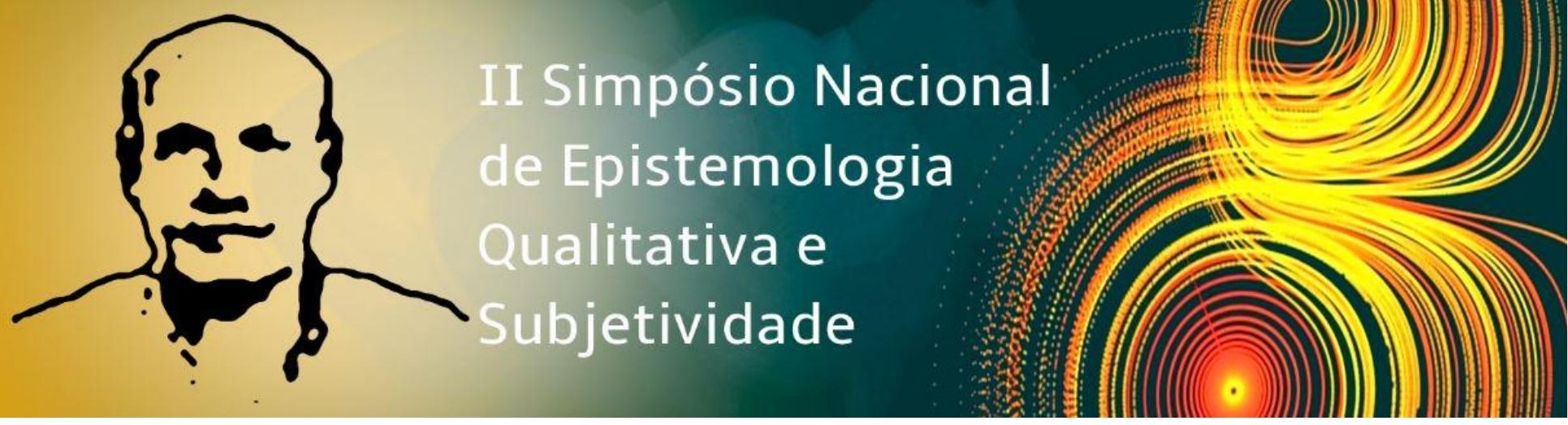

- Eixo temático: 12. A significação da subjetividade em diversos campos: direito, organizações, trabalho comunitário e outros.

\title{
Subjetividade e Alimentação: a comida como uma construção histórico-cultural
}

Elaine Martins Pasquim, Ministério da Ciência, Tecnologia, Inovações e Comunicações, elaine.pasquim@gmail.com

Géssica Mércia Almeida, Universidade Federal de Goiás, gessicamercia@gmail.com

\section{Resumo}

A alimentação é um campo complexo de conhecimento que permite aprofundamentos teóricos em suas diversas dimensões. Carvalho, Luz e Prado (2009) apontam que a comida assume significados e o alimentar-se assume sentidos, relativo à significação no contexto de um universo imaginário e simbólico. Esse universo, nem sempre racional, produz identidades individuais e coletivas, relações sociais com divisões do trabalho, distinção social e vínculos que superam a lógica consciente do discurso. Perceber as configurações e os sentidos subjetivos existentes e construídos sobre o modo de ver, preparar e comer é propiciar uma leitura/reflexão dos interesses, vontades e implicações que se reconstroem no processo histórico cultural da alimentação. Busca-se, assim, realizar o levantamento do estado da arte sobre a subjetividade e sua relação com a alimentação e nutrição. As epidemias simultâneas de obesidade e desnutrição, além das mudanças climáticas em todo o mundo, constituem a maior ameaça global à saúde humana e à do planeta e que deverão ser enfrentadas neste século (SWINBURN, 2019). Diante, desse contexto, emergiu a busca por compreender a relação entre subjetividade e alimentação, entendendo que estas envolvem uma pluralidade de aspectos e dimensões. Gonzalez Rey (2007) aborda a subjetividade humana a partir da perspectiva cultural-histórica. Considera-a inseparável do mundo simbólico da cultura da qual emerge. As discussões identificadas que abordam, em alguns momentos, a questão da subjetividade e alimentação, tendem a ser aquelas que fazem a relação da alimentação, sociedade, antropologia e cultura. Assim, ao relacionar alimentação e cultura, muitos autores trazem à tona questões relativas à intersubjetividade. A alimentação corresponderia às relações humanas mediadas pela comida. A comida, entendida como alimento simbolizado, ganha espaço, no ato de alimentar a si e aos outros, na ordem social, cultural, política, filosófica, psíquica (Klotz Silva et al, 2010, p. 4). As leituras realizadas apontam para discussões de formação de subjetividades sociais relacionadas à alimentação na 


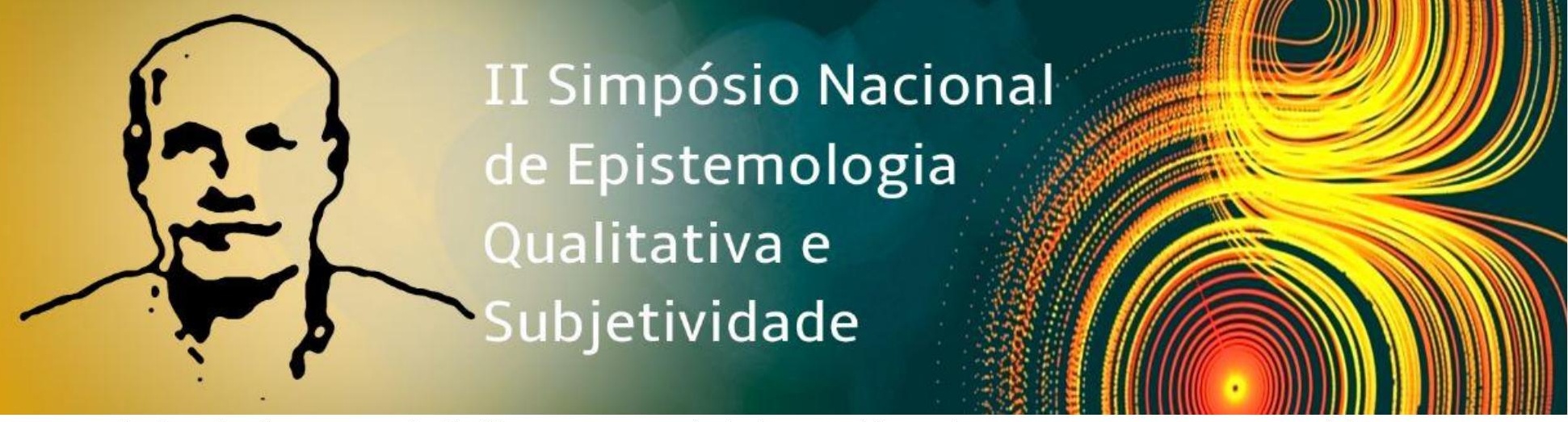

teia de relação entre os indivíduos com a sociedade, considerando o contexto e estrutura social, cultural e histórica. No entanto, não foram encontradas análises da formação de subjetividades que correlacionem as subjetividades sociais com as subjetividades individuais que considerem além dos contextos sociais amplos, as teias singulares de relações das pessoas. De qualquer modo, cabe levantar a discussão e crítica de Gonzalez Rey (2007) quando coloca que a produção de sentidos subjetivos ocorre na rede de relações de uns com os outros (e não apenas sobre a experiência ou representações sociais/ discursos hegemônicos que a significam socialmente). Nesse sentido, apesar de a análise do contexto social ser fundamental, incluindo o poder dos discursos institucionais (médicos, religiosos, familiares, mídia, etc) em relação às representações sociais, é importante que não se omita a trama de vida do sujeito, sua trama subjetivo-relacional. Diante disso, identificamos a necessidade de ampliar pesquisas que possam analisar como esse mundo social configurado nos discursos e nas representações sociais é vivido pelos indivíduos de forma singular dentro do seu sistema único de relações. Uma questão seria como o mundo relacional-afetivo da pessoa se expressa na configuração subjetiva relacionada à alimentação e nutrição.

Palavras chave: subjetividade, alimentação, segurança alimentar e nutricional.

\section{Referências}

CARVALHO, M. C. V. S.; LUZ, M. T.; PRADO, S. D. Comer, alimentar e nutrir: categorias analíticas instrumentais no campo da pesquisa científica. Ciênc. saúde coletiva, vol.16, n.1, pp.155-163, 2011.

SWINBURN, B. A.; KRAAK, V. I.; ALLENDER, S.; ATKINS, V. J.; BAKER, P. I.; BOGARD, J. R.; BRINSDEN, H.; CALVILLO, A.; DE SCHUTTER, O.; DEVARAJAN, R.; EZZATI, M.; FRIEL, S.; GOENKA, S.; HAMMOND, R. A.; HASTINGS, G.; HAWKES, C.; HERRERO, M.; HOVMAND, P. S.; HOWDEN, M.; JAACKS, L. M.; KAPETANAKI, A. B.; KASMAN, M.; KUHNLEIN, H. V.; KUMANYIKA, S. K.; LARIJANI, B.; LOBSTEIN, T.; LONG, M. W.; MATSUDO, V. K. R.; MILLS, S. D. H.; MORGAN, G.; MORSHED, A.; NECE, P. M.; PAN, A.; PATTERSON, D. W.; SACKS, G.; SHEKAR, M.; SIMMONS, G. L.; SMIT, W.; TOOTEE, A.; VANDEVIJVERE, S.; WATERLANDER, W. E.; WOLFENDEN, L.; DIETZ, W. H. The Global Syndemic of Obesity, Undernutrition, and Climate Change: The Lancet Commission report. The Lancet. Vol. 393 February 23, 2019. 791-846

GONZALEZ REY, F. Subjetividade: teoria, epistemologia e método. Campinas, SP: Ed. Alínea, 2017.

KLOTZ SILVA, J.; PRADO, S. D.; CARVALHO, M. C. V.; ORNELAS, T. F. S.; OLIVEIRA, P. F. Alimentação e cultura como campo científico no Brasil. Physis Revista de Saúde Coletiva, Rio de Janeiro, v. 20, n. 2, p. 413-442, 2010. 